\title{
sciendo
}

\section{ANALYSIS OF CORRELATIONS BETWEEN SELECTED BLOOD MARKERS OF LIVER FUNCTION AND MILK COMPOSITION IN COWS DURING LATE LACTATION PERIOD*}

\author{
Ryszard Mordak ${ }^{1 *}$, Robert Kupczyński², Marian Kuczaj ${ }^{3}$, Wojciech Niżański ${ }^{4}$ \\ ${ }^{1}$ Department of Internal Medicine, Faculty of Veterinary Medicine, \\ Wroclaw University of Environmental and Life Sciences, Pl. Grunwaldzki 47, 50-366 Wrocław, Poland \\ ${ }^{2}$ Department of Environment Hygiene and Animal Welfare, Faculty of Biology and Animal Science, \\ Wroclaw University of Environmental and Life Sciences, Chełmońskiego 38 c, 51-630 Wrocław, \\ Poland \\ ${ }^{3}$ Institute of Animal Breeding, Wroclaw University of Environmental and Life Sciences, \\ Chełmońskiego 38 c, 51-630 Wrocław, Poland \\ ${ }^{4}$ Department of Reproduction and Clinic of Farm Animals, Faculty of Veterinary Medicine, \\ Wroclaw University of Environmental and Life Sciences, Pl. Grunwaldzki 49, 50-366 Wrocław, Poland \\ •Corresponding author: ryszard.mordak@upwr.edu.pl
}

\begin{abstract}
The knowledge of the existing levels and the interrelationships between various blood and milk parameters is very useful for the analysis and monitoring of homeostasis in high-yielding dairy cows. The aim of the study was to evaluate these values and correlations for selected blood markers of liver function: aspartate aminotransferase (AST), alanine aminotransferase (ALT), gamma-glutamyl transferase (GGT), bilirubin, albumin, glucose, cholesterol, and selected milk parameters: somatic cell count (SCC), colony-forming units (CFU), fat, protein, lactose, solids, solids non-fat (SNF), and milk production in cows during late lactation period. At the same time blood and milk samples were collected from 11 clinically healthy milking cows in later lactation period. The 11 selected cows were examined once a day for $\mathbf{3}$ days resulting in $\mathbf{3 3}$ sets of blood and milk samples for laboratory and statistical analysis. Significant positive correlations were observed between: ALT and albumin, ALT and cholesterol, GGT and glucose, albumin and cholesterol, CFU and fat, CFU and solids, SCC and protein, fat and solids, protein and SNF, lactose and SNF, GPT and SNF, albumin and protein, albumin and SNF, glucose and fat, as well as significant negative correlations between: AST and ALT, AST and GGT, AST and albumin, CFU and lactose, fat and lactose, fat and SNF, lactose and solids, solids and SNF, AST and SCC, AST and protein, AST and SNF, ALT and fat, ALT and solids, glucose and solids, cholesterol and CFU. The results obtained may be important for detecting of different biochemical pathways and helpful in estimating, predicting or determining trends, the direction of changes in liver functions and assessing the risk of alert levels for liver blood markers, when only daily results of milk parameters are available.
\end{abstract}

Key words: cows, liver function, blood, milk, parameters, correlations

*The costs of publishing was financed under the Leading Research Groups support project from the subsidy increased for the period 2020-2025 in the amount of $2 \%$ of the subsidy referred to Art. 387 (3) of the Law of 20 July 2018 on Higher Education and Science, obtained in 2019. 


\section{Background}

Constant monitoring of high-yielding cows kept in large herds is useful for assessing animal welfare and health as well as for early diagnosis of many health problems (Nordlund, 2005; Cook et al., 2006). Appropriate use of clinical and laboratory diagnostics is important in veterinary practice for identifying, preventing, and treating not only infectious diseases but also nutritional and metabolic health problems as well as to control the results of therapy in dairy cows (Staufenbiel and Gelfert, 2004; Whitaker et al., 2005; Mordak and Nicpoń, 2006). Metabolic disorders caused by deficiency of nutrients, energy, vitamins or minerals are particularly important because they are very common in dairy herds, especially during the transition period, in early lactation, and also in the later lactation period and they have a significant impact on health, reproduction level and milk production in cows (LeBlanc, 2010, 2012). In addition, the early detection of subclinical imbalances, especially in relation to mammary glands, milk production and liver function, helps to eliminate or minimize the occurrence of diseases in the herd, and helps to reduce costs of treatment and culling of cows (Bobe et al., 2004; Ametaj, 2005; Djokovic et al., 2013).

Biochemical and morphological analysis of blood can be carried out with sufficient frequency depending on risk analysis determined by the level of milk production, quality of nutrition, management, season, and a representative number of animals on the farm and in different technological groups (Aschenbach et al., 2010; Cozzi et al., 2011; Brscic et al., 2015). In many modern dairy farms in the UK, blood metabolic profiles in high-yielding cows are usually checked several times a year, when the average milk yield exceeds 10,000 liters during the lactation period, especially when the herd is at high risk of metabolic diseases (Whitaker et al., 2005; Staufenbiel and Gelfert, 2004). Clinical and laboratory monitoring of subclinical nutritional and metabolic diseases in dairy cows usually involves the transition period and the early lactation period, especially for the detection of subclinical forms of hypocalcemia, ketosis and sub-acute rumen acidosis (Cook et al., 2006). Because the risk of such problems in the third lactation phase (considered as above two hundred days after calving) is low, blood samples of cows are rarely monitored at this time. Laboratory monitoring in dairy cows usually reveals shortage of minerals and energy due to inadequately low levels of elements or improperly high levels of non-esterified fatty acids (NEFA), ketone bodies (BHB), activity of liver enzymes and many other abnormalities often present especially in high-yielding animals during the transition period or during the later lactation period (Bronicki and Dembiński, 1994; Lippi et al., 2007; Kalaitzakis et al., 2007; Gonzalez et al., 2011).

Examination of appropriate markers of liver function, such as: the activity of AST, ALT, GGT enzymes, as well as the concentration of bilirubin, albumin, glucose and cholesterol in blood serum, allows for an overall assessment of liver processes, but also the production potential of dairy cows (Djokovic et al., 2013). Because the milk yield and milk quality of cows depends on their internal metabolic homeostasis, including liver processes, they can potentially be measured or linked to the values of various milk components such as: fat, protein, lactose and others (Djokovic et al., 2019). 
In many countries and regions, different metabolic monitoring systems are implemented to assess the health of dairy cows using milk samples, including new and very useful laser techniques such as Visible Near Infrared Spectroscopy (Aernouts et al., 2011; Baines and Herbrink, 2013).

Dairy farms usually do not systemically monitor blood in high-yielding cows in the later stages of lactation. Also, veterinary laboratories rarely carry out simultaneous biochemical or morphological tests of blood and milk for comparative analysis. Only rarely are such tests repeated at specific short intervals, (e.g. daily), allowing tracking of changes in internal homeostasis, and mutual relationships between individual parameters and the progression of diseases. Individual values obtained from blood and milk are usually analyzed only in relation to standard reference limits. Modern practice, however, requires more frequent, and even daily monitoring of the health of high-yielding dairy cows, to control the quantity and quality of milk production and management of various potential health problems. However, this model of monitoring is very difficult and expensive to implement and maintain. There are no detailed literature data on the simultaneous monitoring of blood and milk parameters in the third lactation period in dairy cows.

In the available scientific literature there is a lack of data on complex analysis of the interdependence and degree of correlation between different blood and milk parameters or between profiles at daily intervals. The need for such a method of monitoring arose from the observed daily and daily significant fluctuations in milk production in cows during this period of lactation. We hypothesize that differences in daily milk yield and milk composition may be due to the metabolic and/or secretory function of the liver.

The aim of the study was to analyze the correlations or interrelationships between selected blood markers of liver functions and milk parameters in cows during the late lactation period.

\section{Material and methods}

\section{Animals and study design}

The study protocol was approved by the 2nd Local Bioethics Committee in Wrocław (decision no. 24/2007). Randomly selected 11 Black-and-White Holstein Friesian cows aged 4-5 years, with a similar body condition scoring (BCS) value of about 3.5-4.0 in a five-point scale system and moderate milk production were included in the study. Cows monitored were representative of a technological group with a similar lactation period (second half of the lactation period - on an average 218 days after calving) on the same dairy farm in autumn (October). The herd of cows was free of common infectious diseases (monitored and controlled by the veterinary office) and the average milk yield was about $8500 \mathrm{~kg}$ per lactation. Cows did not show symptoms of any disease during clinical examinations, but they were in a herd and at a time of normal risk for metabolic diseases and mastitis, usually occurring in typical winter conditions in high-yielding animals. Each of 11 selected 
cows was examined and milk and blood samples were collected once a day for three consecutive days. Thus 33 sets of blood and milk samples were obtained within three days from 11 cows for laboratory and statistical analysis. All the samples were obtained at the same time, but milk samples were collected during morning milking using special devices (milk meters), while blood samples were collected immediately after the morning milking at around 5:00. In cows 10-ml Sarstedt polypropylene tubes were used to collect blood from the external jugular vein, while 50-ml Prolab polypropylene containers were used to collect a representative sample of milk. Blood and milk samples from the time of collection were delivered to two appropriate laboratories within 1 hour. The cows were kept in the same, favorable environmental conditions in a facility designed for 90 milking cows with free access to stalls. These animals were provided with high environmental comfort (mattresses, automatic ventilation system) and nutrition (feed table with total mixed ration and stations with electronic system for dry ration). The cows were fed a uniform feed ration using a standardized total mixed ration (TMR) based on corn silage, alfalfa-grass silage, high moisture corn, alfalfa-grass hay, barley straw, rapeseed meal, soybean meal, minerals, vitamins, supplemented with a commercial mix of concentrates for lactating animals according to their daily milk yield. Nutrient composition of TMR was: NEL 6.12 MJ/kg, crude protein 16.8\%, crude fat 3.80\%, NDF 36.2\%, ADF $22.4 \%$ (according to AOAC methods). Fresh TMR was given to cows ad libitum twice a day in the morning and afternoon (allowing 5\% refusals). The cows had free access to fresh water. A 2x4 milking parlor (Alpro-Delaval system) was used on the farm. At the farm, the cows were milked twice a day at 5:00 and 15:00 h, and milk yield was automatically recorded.

\section{Blood analysis}

Blood samples were collected from the external jugular vein and parameters of the hepatic profile were analyzed in the biochemical examination of the blood serum: the activity of AST, ALT, GGT, total bilirubin, albumin, glucose and cholesterol. These blood tests were performed at a specialized laboratory in the Faculty of Veterinary Medicine (Department of Internal Medicine), University of Environmental and Life Sciences in Wroclaw. Measurements of the activity of the AST, ALT, and GGT enzymes, and concentrations of total bilirubin, albumin, glucose and cholesterol were made using the Pointe-180 (Pointe Scientific Poland) analyzer, while albumin levels were determined using the Kodak-DTSC II Ektachem (Eastman Kodak Company USA) analyzer. Limits on reference standards were used for the interpretation of the values of individual diagnostic blood parameters.

\section{Milk analysis}

The study also used the samples of milk taken automatically from all phases of milking. These milk samples were collected in special reservoirs analogous to those used in the trial milking. The collected milk samples were analyzed for basic morphological and biochemical parameters of milk: SCC, CFU, the proportions (fractions) of fats, proteins, lactose, solids and solids non-fat contents in milk. The analysis also included milk yield as production parameter, during the morning milking when 
the blood and milk samples were taken. Biochemical analyses of milk were carried out in a specialized laboratory for milk in the University of Environmental and Life Sciences in Wroclaw. An SCC assay was performed using a SOMACOUNT-150 (Bentley, USA) analyzer by employing the fluoro-opto-electronic method. CFU determination was performed by flow cytometry on a BACTOCOUNT-70 (Bentley, USA) analyzer. Determination of the fractions of milk fat, protein, lactose, solids, and SNF was done by a Milko-Scan 133 B (Foss Electric, Denmark) analyzer. Milk yield was recorded by the Alpro-Delaval electronic system.

\section{Statistical analysis}

Statistical analysis was carried using the Statistica 10 StatSoft Inc. program. All samples were tested for normal distribution with the Shapiro-Wilk test. Linear regression was used to assess the level of linear relationships between changes in the values of the individual and Pearson's correlation coefficient (r) was calculated. Each determined coefficient was then tested for statistical significance with the Student's t-test for n-2 degrees of freedom. The number of samples was 33 and the value of the correlation coefficient determining the threshold for a statistical significance level of $5 \%(\mathrm{P}<0.05)$ was $\mathrm{r}=0.344$. The values of the Pearson's correlation coefficients between the variables, also indicating their statistical significance, are presented in the appropriate results sets (1-3).

\section{Results}

The results of the linear relationships between the blood biochemical parameters of the basic liver profile and basic milk assessment parameters as well as their mutual relationships are shown in the results sets $1-3$. The values of Pearson's correlation coefficients between variables exceeding the limit of significant statistical correlations are specially marked. The average values and standard deviations for blood and milk parameters are presented in Table 1.

Result set 1. Levels of linear relationships between selected blood markers of liver function

\begin{tabular}{l|c|c|c|c|c|c|c}
\hline & AST & ALT & GGT & Bilirubin & Albumin & Glucose & Cholesterol \\
\hline AST & & & & & \\
ALT & $-\mathbf{0 . 5 0 3 *}$ & & & & & \\
GGT & $-\mathbf{0 . 3 6 2 *}$ & 0.279 & & & & \\
Bilirubin & 0.018 & 0.104 & -0.141 & & & \\
Albumin & $-\mathbf{0 . 5 6 5 *}$ & $\mathbf{0 . 4 5 1 *}$ & 0.310 & 0.141 & & \\
Glucose & -0.238 & 0.274 & $\mathbf{0 . 5 1 7 *}$ & -0.171 & 0.158 & \\
Cholesterol & -0.313 & $\mathbf{0 . 7 2 5 *}$ & -0.117 & 0.049 & $\mathbf{0 . 4 4 9 *}$ & 0.043 \\
\hline
\end{tabular}

* - significant statistical correlation, AST - aspartate aminotransferase, ALT - alanine aminotransferase, GGT - gamma-glutamyl transferase. 
AST activity was significantly and negatively correlated with the activity of ALT $(\mathrm{r}=-0.503)$ and GGT $(\mathrm{r}=-0.362)$ and albumin concentration $(\mathrm{r}=-0.565)$ in blood serum.

ALT activity was significantly and positively correlated with the concentration of albumin $(\mathrm{r}=0.451)$ and serum cholesterol $(\mathrm{r}=0.725)$.

GGT activity correlated positively and significantly with the glucose concentration in the blood ( $\mathrm{r}=0.517)$.

The concentration of albumins in the blood serum positively correlated with serum cholesterol concentration $(\mathrm{r}=0.449)$.

Result set 2. Levels of linear relationships between selected parameters of milk assessment

\begin{tabular}{|c|c|c|c|c|c|c|c|c|}
\hline & Production & $\mathrm{CFU}$ & $\mathrm{SCC}$ & Fat & Protein & Lactose & Solids & SNF \\
\hline \multicolumn{9}{|c|}{ Production } \\
\hline $\mathrm{CFU}$ & -0.052 & & & & & & & \\
\hline $\mathrm{SCC}$ & -0.190 & -0.057 & & & & & & \\
\hline Fat & 0.010 & $0.428 *$ & 0.049 & & & & & \\
\hline Protein & -0.223 & -0.148 & $0.363 *$ & -0.285 & & & & \\
\hline Lactose & 0.213 & $-0.433^{*}$ & -0.198 & $-0.779 *$ & 0.003 & & & \\
\hline Solids & -0.014 & $0.390 *$ & 0.119 & $0.970 *$ & -0.065 & $-0.751^{*}$ & & \\
\hline SNF & -0.094 & -0.335 & 0.227 & $-0.619 *$ & $0.881 *$ & $0.475^{*}$ & $-0.475 *$ & \\
\hline
\end{tabular}

* - significant statistical correlation, CFU - colony-forming units, SCC - somatic cell count, SNF - solids non-fat in milk.

Result set 3. Levels of linear relationships between selected blood markers of liver function and parameters of milk assessment

\begin{tabular}{lcc|c|c|c|c|c}
\hline & AST & ALT & GGT & Bilirubin & Albumin & Glucose & Cholesterol \\
\hline Production & 0.300 & 0.046 & -0.058 & -0.043 & -0.185 & 0.253 & 0.224 \\
CFU & 0.163 & -0.260 & -0.497 & -0.287 & -0.056 & 0.031 & $-\mathbf{0 . 4 7 6 *}$ \\
SCC & $\mathbf{- . 3 8 0 *}$ & 0.001 & 0.097 & -0.158 & -0.332 & 0.121 & 0.011 \\
Fat & 0.249 & $\mathbf{- 0 . 4 4 5 *}$ & -0.293 & 0.144 & -0.165 & $\mathbf{0 . 4 8 5 *}$ & -0.117 \\
Protein & $-\mathbf{0 . 6 4 8 *}$ & 0.247 & 0.302 & 0.137 & $\mathbf{0 . 4 4 9 *}$ & 0.246 & 0.019 \\
Lactose & 0.091 & 0.294 & 0.040 & -0.170 & 0.042 & 0.192 & 0.242 \\
Solids & 0.129 & $-\mathbf{0 . 4 0 8}^{*}$ & -0.253 & 0.179 & -0.062 & $-\mathbf{0 . 4 7 4 *}$ & -0.088 \\
SNF & $\mathbf{- . 5 2 7 *}$ & $\mathbf{0 . 3 5 7 *}$ & 0.288 & 0.038 & $\mathbf{0 . 4 1 3 *}$ & 0.308 & 0.132 \\
\hline
\end{tabular}

* - significant statistical correlation, CFU - colony forming units, SCC - somatic cell count, SNF - solids non-fat in milk.

Milk yield showed no significant correlation with any of the studied milk parameters $(\mathrm{r}<0.344)$.

The number of microorganisms in milk (CFU) was positively correlated with fat content $(\mathrm{r}=0.428)$ in the milk and solids $(\mathrm{r}=0.390)$, but negatively correlated with the concentration of lactose in milk $(\mathrm{r}=-0.433)$. Increase in SCC significantly increased proteins in milk $(\mathrm{r}=0.363)$. 
Very high significant positive correlation was observed between the fat content of milk and solids $(\mathrm{r}=0.970)$. Also high significant negative correlations between milk fat and SNF $(r=-0.619)$ and milk fat and lactose $(r=-0.779)$ were noted.

A positive correlation of milk proteins with SNF was observed. There was negative correlation of milk lactose with solids and positive correlation with SNF. Significant negative correlation between solids and SNF was noted with $\mathrm{r}=-0.475$.

AST activity in blood serum correlated significantly and negatively with SCC, concentration of milk proteins and SNF.

ALT activity in blood serum was negatively correlated with the content of milk fat and solids, and positively with SNF.

No significant correlations were observed between GGT as well as serum bilirubin and the tested components of milk.

Serum albumins were positively correlated with milk proteins and SNF.

The concentration of glucose in blood serum was positively correlated with the concentration of milk fat and negatively with solids.

Serum cholesterol was positively correlated with milk CFU.

\section{Discussion}

Understanding the causes of the changes in the values of individual milk components, especially of fat, protein, and lactose is fundamental to managing the cows' metabolism and their health (Ametaj, 2005; Bailey et al., 2005; Djokovic et al., 2019). These parameters of milk quantity and quality can show the current conditions of the mammary glands and liver function in cows. In addition, the liver is an important organ that contributes to the production of milk in cows, and liver function has a significant impact on the level of many blood parameters and on various systems of the body (Tanaka et al., 2013; Djokovic et al., 2019). Levels of liver enzymes such as AST, ALT, and GGT as well as levels of serum concentrations of bilirubin, albumin, glucose and cholesterol are parameters of the liver profile commonly used in medicine as an indicator of liver function (Aschenbach et al., 2010).

In order to determine the relationship between blood lipomobilization and liver function indicators or between milk parameters and udder function in high-yielding dairy cows, more scientific research was carried out in the periparturient period or in the early postnatal period (Kalaitzakis et al., 2007; Gonzalez et al., 2011; Djokovic et al., 2019).

Slightly elevated parameters such as AST and total bilirubin may have been due to increased current liver burden or subclinical inflammatory, toxic or degenerative conditions (Davoudi, 2013). The recorded activity of the AST parameter was negatively correlated with the activity of ALT and GGT and the concentration of albumin in blood serum. Such a negative correlation can often be observed in cows with high milk production and liver metabolic load, with or without visible damage to hepatocytes, and especially during the increase of mitochondrial function or damage to the structure of these mitochondria (Gonzalez et al., 2011). The ALT activity was 
positively correlated with the concentration of albumin and serum cholesterol. This may also be associated with a higher rate of liver metabolism in high-yielding cows, as already mentioned for the correlation of albumin in milk. In contrast to AST, ALT is a cytoplasmic enzyme and in cattle, its activity in hepatocytes is small compared to other species (Stojević et al., 2005). Moreover, ALT is involved in the metabolism of proteins, catalyzing a reversible reaction of $\alpha$-alanine synthesis (Rimac and Bojić, 2017). The higher GGT activity observed in dry cows, both primiparous and multiparous, compared with heifers might be a long-term effect of the hepatic stress induced by the preceding lactation, because GGT plasma activity tends to increase in cases of chronic liver disorders (Brscic et al., 2015). GGT activity correlated positively with the concentration of glucose in the blood. GGT is an enzyme that catalyzes the biochemical processes associated with the transfer of glutamate groups, present in glutamic acid, a key amino acid in cellular metabolism of proteins (Rimac and Bojić, 2017). This enzyme is found in different tissues especially in the liver, and it has a significant role in medicine as a good diagnostic marker in the assessment of metabolic health of dairy cows (Bertoni and Trevisi, 2013). The increased concentration of this enzyme may be associated with impaired secretion of bile, congestive hepatitis as well as the intensive metabolism of proteins and amino acids accompanying tumor processes or extremely intensified gluconeogenesis and usually reflects liver damage in dairy cattle (Bronicki and Dembiński, 1994; Aschenbach et al., 2010; Cozzi et al., 2011). However, the significant parity effect observed for this parameter in healthy cows could be the result of major productive stress in multiparous cows (Cozzi et al., 2011) and can depend on the breed and BCS (Kupczyński et al., 2011). A significant association of serum GGT activity with fasting plasma glucose (FPG) and triglycerides was observed in humans and it was biologically explained by underlying mechanisms such as hepatic steatosis, insulin resistance, and increased oxidative stress (Lippi et al., 2007).

Gluconeogenesis is particularly intense in highly productive and inadequately fed dairy cows, which readily develop negative energy balance (NEBAL), ketosis, and metabolic fatty degeneration and dysfunction of the liver (Ametaj et al., 2002; Goff, 2006; LeBlanc, 2011). Typical subclinical fatty liver complex is usually observed in the early post-parturient period, but later, 4-6 weeks after calving, it is seen as a clinical syndrome and seen rarely in other periods of lactation (Kalaitzakis et al., 2007; Gonzalez et al., 2011; Esposito et al., 2014). Monitoring of the internal homeostasis in highly yielding cows by the use of the respective parameters measured in the blood and milk seems to be a necessity in today's modern dairy farms (Bobe et al., 2004; Staufenbiel and Gelfert, 2004; Whitaker et al., 2005; Cook et al., 2006; Filipejová and Kováčik, 2009; LeBlanc, 2010; Mordak and Stewart, 2015). It should also be noted that GGT shows greater specificity in cattle liver than AST and ALT (Stojević et al., 2005). Moreover, positive correlations between AST and BHB $(\mathrm{P}<0.05, \mathrm{r}=0.540)$ as well as between AST and NEFA $(\mathrm{P}<0.05, \mathrm{r}=0.590)$ were observed by other authors in cows with lipid infiltration in liver (Djokovic et al., 2013). An interesting observation was that serum glucose concentration was not significantly correlated with other investigated liver function parameters. This may be due to high compensation of the gluconeogenesis process by the regulation of glucagon 
and insulin observed even during the steatosis of the liver in dairy cows (Kalaitzakis et al., 2006; Aschenbach et al., 2010).

Total serum bilirubin is a valuable parameter in diagnostics, especially when its level is elevated in cows with fatty liver, or anorexia or immediately after calving (Kalaitzakis et al., 2007). In addition, clinical prognosis is rather uncertain for cows with moderate and severe hepatic steatosis and when total serum bilirubin levels are high. Because the cows selected for the study were clinically healthy and tested at a later stage of lactation when milk production usually decreases gradually, only normal serum values of total bilirubin were observed in the results (Table 1).

Table 1. The mean values and standard deviations of the tested samples of blood serum and milk parameters in cows

\begin{tabular}{l|c|c|c|c}
\hline \multicolumn{1}{c|}{$\begin{array}{c}\text { Parameter of } \\
\text { blood serum or milk }\end{array}$} & $\begin{array}{c}\text { Mean } \\
\overline{\mathrm{x}}\end{array}$ & $\mathrm{SD} \pm$ & Unit & $\begin{array}{c}\text { Reference values } \\
\text { (Meyer and Harvey, } \\
\text { 2004) }\end{array}$ \\
\hline Serum AST & 67.90 & 13.99 & $\mathrm{U} / \mathrm{L}$ & $48-100$ \\
Serum ALT & 28.83 & 5.35 & $\mathrm{U} / \mathrm{L}$ & $17-37$ \\
Serum GGT & 41.03 & 7.42 & $\mathrm{U} / \mathrm{L}$ & $20-48$ \\
Serum cholesterol (total) & 4.23 & 1.20 & $\mathrm{mmol} / \mathrm{L}$ & $2.26-6.60$ \\
Serum albumin & 29.69 & 2.37 & $\mathrm{~g} / \mathrm{L}$ & $27-43$ \\
Serum glucose & 3.07 & 0.31 & $\mathrm{mmol} / \mathrm{L}$ & $2.04-3.91$ \\
Bilirubin (total) & 4.05 & 2.37 & $\mu \mathrm{mol} / \mathrm{L}$ & $1.9-5.1$ \\
Milk production (1 morning milking) & 16.53 & 2.63 & $\mathrm{liters}$ & \\
Milk CFU & 82.77 & 52.12 & $\times 1000 / \mathrm{ml}$ & \\
Milk SCC & 114.36 & 63.74 & $\times 1000 / \mathrm{ml}$ & \\
Milk fat & 4.30 & 1.81 & $\%$ & \\
Milk protein & 3.57 & 0.42 & $\%$ & \\
Milk lactose & 4.64 & 0.22 & $\%$ & \\
Milk solids & 13.14 & 1.56 & $\%$ & \\
Milk SNF & 8.82 & 0.48 & $\%$ & \\
\hline
\end{tabular}

AST - aspartate aminotransferase, ALT - alanine aminotransferase, GGT - gamma-glutamyl transferase, CFU - colony forming units, SCC - somatic cell count, SNF - solids non-fat.

Serum albumin concentration fluctuated around the lower reference limit and was positively correlated with serum cholesterol value. This correlation in physiological conditions is probably related to albumin biochemical functions. Albumins, often referred to as molecular transporters, serve as carriers for molecules with low water content, including fat-soluble hormones, bile salts, unconjugated bilirubin, free fatty acids, and cholesterol (Sankaranarayanan et al., 2013; Rimac and Bojić, 2017). In addition, albumin and endogenous cholesterol are produced significantly in the same place in liver cells hepatocytes. In other clinical cases in cows, low lev- 
els of serum albumin (hypoalbuminemia) and serum cholesterol may be associated with hepatocyte dysfunction, fat infiltration, degeneration and damage to liver tissue often observed during NEBAL or anorexia (Gonzalez et al., 2011; Farid et al., 2013). Albumins are also negative acute phase proteins, and their low serum levels can be found in various acute or chronic inflammations (Ametaj et al., 2002). In the cows tested, slightly reduced serum albumin levels may have been caused by testing and slightly reduced feed intake, which only confirms the need to monitor the internal homeostasis of high-yielding animals also in late lactation.

Milk production based on the volume obtained during the morning milkings about 5 am (and not the daily production) did not show any significant correlation with any of the biochemical parameters tested. This lack of significant correlation seems to be understandable because the potential production of cows is affected by many different factors, not only metabolic but also genetic and environmental such as management, nutrition, body condition, rumen function, season and many others (Jóźwik et al., 2012).

The number of bacteria in cow milk (CFU) correlated positively with fat content and solids, and negatively with lactose concentration. In cow milk with increased bacterial contamination, occurring during subclinical infection of the mammary glands or, especially, during clinical mastitis, there is usually an elevated number of bacteria and SCC and an increased amount of protein, but at the same time a reduced level of fat is observed (Olechnowicz and Jaśkowski, 2012). In other studies of subclinical mastitis in cows, milk had a reduced content of lactose, solids fat and total solids, but there was no difference in protein and fat between quarters of infected and non-infected udders (Malek dos Reis et al., 2011). The cited authors concluded that intramammary infections in cows altered milk composition; however, the degree of change depended on the mastitis-causing pathogen which affected protein, lactose, solids non-fat, and total solids content, but not milk fat content. In addition, the cited studies showed that SCC was negatively associated with a reduced content of lactose and solids in milk. As observed in our own research on healthy cows (without mastitis), low levels of CFU and SCC are not seen as resulting from infection, but suggest a lack of significant inflammatory response. In these healthy cows the observed positive correlations between $\mathrm{CFU}$ and milk fat are in contrast to the observation in cows with mastitis.

Relatively high positive correlation was observed between milk fat content and solids. This could explain the strong impact of milk fat content on the solids content in milk. The natural result of this ratio results in a negative correlation between milk fat and SNF, because this last parameter does not include fats.

Interestingly, in addition, significant negative correlations between fat and lactose in milk were recorded in the results. This demonstrates some metabolic competitiveness between fat and lactose content in milk. About $80 \%$ of lactose is produced from glucose and about $20 \%$ from acetate, which is highly competitive in the formation of milk fat produced from glycerol resulting from the transformation of glucose (Rimac and Bojić, 2017). Milk fat can also be produced from volatile fatty acids, and inter alia from the acetic acid formed in the rumen of cows (Liu et al., 2018). The results of the cited authors indicated that lactation performance and milk fat synthe- 
sis increased with branched-chain volatile fatty acids supplementation by improving ruminal fermentation, nutrient digestibility and mRNA expressions of genes related to milk fat synthesis.

The high significant and positive correlation between milk proteins and solids non-fat (SNF) in milk recorded in the results is completely expected, because milk proteins have a significant contribution in this mass. The relatively high negative correlation of milk lactose with milk solids revealed that lactose in milk did not significantly affect milk solids, as was the case with fat. Milk lactose as a non-fatty compound was, logically, positively correlated with SNF. The inverse correlation between the values of solids and SNF confirms the above natural dependence.

In the obtained results, serum AST activity correlated negatively with SCC, which is interesting and quite difficult to explain. However, it should be kept in mind that the cows in question were clinically healthy and did not show mastitis in specialist veterinary studies, but they were intensively fed. AST activity in blood serum showed a negative correlation with the concentration of milk proteins and SNF. This relationship may show the need to increase the metabolic efficiency of hepatocytes mitochondria to produce milk in mammary glands with a higher protein content. In addition, AST is an enzyme associated with the synthesis of protein alpha-amino acids and $\alpha$-keto acids and aspartic acid in cows; so high concentrations of milk protein and milk fat are dependent on the proper functioning of the liver (Rezaei et al., 2016). Other authors showed no significant correlation between AST and milk protein or ALT and milk protein, but their studies concerned cows in different lactating periods (Djokovic et al., 2019).

ALT activity in serum is used as an additional marker of liver function and liver damage, even in subclinical cases in cows; however, in some cases of structural changes of hepatocytes, the increase of this activity may be insignificant (Stojević et al., 2005). The activity of this alanine aminotransferase in blood serum was significantly negatively correlated with the content of milk fat and solids, but positively correlated with SNF. These correlations additionally confirm the importance of biochemical pathways associated with the liver function shown above (Rezaei et al., 2016). GGT as a test parameter in blood serum showed similar directions of dependence on milk parameters as ALT; however, these relationships were below the level of statistical significance. Significant and negative correlations revealed between ALT and milk fat in the course of own research were not obtained by other authors, however their correlation coefficients for biochemical metabolites in milk and blood were calculated jointly for cows in various groups, also in early and middle lactation (Djokovic et al., 2019). The cited authors found in cows examined at various stages of lactation a significant positive correlation between AST and milk fat $(\mathrm{P}<0.05$, $\mathrm{r}=0.429)$ as well as a significant and negative correlation between blood cholesterol and milk fat $(\mathrm{P}<0.05, \mathrm{r}=0.353)$.

Blood albumin was positively correlated with milk proteins and SNF. The amount of serum albumin can naturally translate into protein content in milk, because serum albumin is a common constituent of body fluids, both in plasma and in the milk of various mammals, especially in dairy cows (Lieske et al., 2005). Serum albumin is the main protein found in blood plasma amounting to $60 \%$ of the total protein, but 
the observed serum albumin concentration does not show a positive correlation with the number of SCC, as in the case of total serum protein or blood globulin (Bobbo et al., 2017). The observed correlation between serum albumin as an acute (negative) phase protein, and SCC was negative and just at the limit of significance - exactly at $r=0.332$, while $r= \pm 0.344$ indicated $p=0.05$.

The concentration of glucose in blood serum correlated positively with the concentration of milk fat and negatively with solids in the obtained results. While analyzing these results it was observed that both parameters, ALT activity and the concentration of glucose in blood serum, are connected to each other through the metabolic pathways of the organism with their participation in milk fat content but in the opposite direction. Milk fat in cows is made of glycerol and fatty acids, but biochemically, glycerol is formed during the transformation of glucose, and saturated fatty acids from plant fiber fermentation in the rumen. Moreover, milk fatty acid composition may be an indicator of energy status in high-yielding cows (Vranković et al., 2017). The quoted authors also noted that glucose was the basic energy-supplying compound in the body but, especially in the case of high-yielding cows, the transformation of glucose was closely related to liver functions, where the relevant enzymes present in hepatocytes allowed conversion of glycerol to glucose to reverse the process on the corresponding pathways of gluconeogenesis and glycolysis.

Very interesting is the lack of correlation between serum glucose in blood and milk lactose in the examined cows. Although glucose is the main precursor of lactose, its synthesis in the milk glands of lactating cows is a process rather poorly understood (Lin et al., 2016). The cited authors concluded that glucose induced cell growth and lactose synthesis in the mammary epithelial cells of dairy cows, but protein kinase B alpha acted as a metabolism regulator in the mammary glands of dairy cows to mediate the effects of glucose on lactose synthesis. Moreover in lactating cows, the mammary glands can consume near $90 \%$ of the circulating glucose.

The negative correlation between serum cholesterol and milk CFU is very interesting and many aspects may be important for discussion. Cholesterol is essential for proper membrane structure and functions in eukaryotic cells, mainly associated with membrane fusion, phagocytosis, oxidative stress and apoptosis but, it is also considered a critical factor in host cell colonization by different bacterial pathogens (Gilk et al., 2013). In addition, cholesterol, as a steroidal lipid, which can react as an alcohol or alkene, is a precursor to the synthesis of important steroids, not only sex hormones and bile acids, but also corticosteroids, vitamin D and other active compounds that can also play a significant role in the body's response to bacterial invasion. Moreover higher levels of blood serum cholesterol, hypercholesterolemia, can lead to cholesterol accumulation in macrophages and other immune cells, promoting inflammatory processes, including augmentation of Toll-like receptor (TLR) signaling, production of cytokines and chemokines, inflammasome activation, and the production of monocytes and neutrophils in the bone marrow and spleen and, finally to amplification of the inflammatory response (Tall and Yvan-Charvet, 2015). Cholesterol homeostasis is also an important factor in the regulation of hematopoiesis, and elevated cholesterol levels are known to promote proliferation and mobiliza- 
tion of hematopoietic stem cells (HSCs), which is also important in inflammatory response (Oguro, 2019).

Because the presented diagnostic issues are very extensive, a wider and more complete analysis of internal homeostasis of highly productive dairy cows, in the context of other important metabolic profiles like: renal, bone-mineral, morphological in relation to raw milk will be presented in separate publications. If other authors presented the dependence of liver profile parameters and milk parameters, they based them on the results obtained in relation to the occurrence of various health disorders like ketosis, abomasal displacement, retained placenta, and low milk productivity or on a single series of tests performed at a more distant date or performed in different groups of lactating cows (Semacan, 2005; Bionaz et al., 2007; Staufenbiel et al., 2007; Filipejová and Kováčik, 2009; Djokovic et al., 2019).

\section{Conclusions}

Studying the correlation between different blood and milk parameters is important not only for monitoring, but also for the potential discovery of relationships of important metabolic pathways from the point of view of physiology and pathology of highly productive animals. The presented dynamic diagnostic model has proved to be a useful tool for detailed assessment of homeostasis, better than a single analytical model. This is particularly important due to the frequent occurrence of subclinical metabolic health problems in high-yield dairy herds.

The obtained results show many interesting and significant relationships between selected blood markers for liver function and milk parameters in dairy cows monitored dynamically in the later lactation period. Significant positive correlations were observed between: ALT and albumin, ALT and cholesterol, GGT and glucose, albumin and cholesterol, CFU and fat, CFU and solids, SCC and protein, fat and solids, protein and SNF, lactose and SNF, GPT and SNF, albumin and protein, albumin and SNF, glucose and fat, as well as significant negative correlations between: AST and ALT, AST and GGT, AST and albumin, CFU and lactose, fat and lactose, fat and SNF, lactose and solids, solids and SNF, AST and SCC, AST and protein, AST and SNF, ALT and fat, ALT and solids, glucose and solids, cholesterol and CFU. The results obtained may be helpful in estimating, predicting, and determining trends, the direction of changes in the liver's internal functions and assessing the risk of alert levels for liver blood markers when only daily results of milk parameters are available.

It seems that the revealed values of individual correlations can be used in practice for direct comparative diagnostics, as well as for analyzers or electronic programs based on indirect algorithmic processing of obtained data from dairy cows.

\section{References}

A ernouts B., P o lshn E., La m m erty n J., S a e y s W. (2011) Visible and near-infrared spectroscopic analysis of raw milk for cow health monitoring: reflectance or transmittance? J. Dairy Sci., 94: 5315-5329. 
A metaj B.N. (2005). A new understanding of the causes of fatty liver in dairy cows. Adv. Dairy Technol., 17: 97-112.

A metaj B.N., Bradford B.J., B obe G., Lu Y., Nafikov R., Sonon R.N., Young J.W., B e it z D.C. (2002). Acute phase response indicates inflammatory conditions may play a role in the pathogenesis of fatty liver in dairy cows. J. Dairy Sci., 85 (Suppl 1): 189.

A s chen b a ch J.R., Kris ten s en N.B., D on kin S.S., H a m m o n H.M., P e n n e r G.B. (2010). Gluconeogenesis in dairy cows: the secret of making sweet milk from sour dough. Life, 62: 869-877.

B a i l e y K.E., J o n e s C.M., H e in r i c h s A.J. (2005). Economic returns to Holstein and Jersey herds under multiple component pricing. J. Dairy Sci., 88: 2269-2280.

B a in es J.R., H e r brink J. (2013). Online milk analysis. Cattle Pract., 21: 218-221.

B ertoni G., Trevis i E. (2013). Use of the liver activity index and other metabolic variables in the assessment of metabolic health in dairy herds. Vet. Clin. North Am. Food Anim. Pract., 29: 413-431.

Bionaz E., Trevisi E., Calamari L., Librandi F., Ferrari A., Bertoni G. (2007). Plasma paraoxonase, health, inflammatory conditions and liver function in transition dairy cows. J. Dairy Sci., 90: 1740-1750.

B obbo T., Fi or e E.M., Gi a ne sella M., M organ te M. (2017).Variation in blood serum proteins and association with somatic cell count in dairy cattle from multi-breed herds. Animal, 11: 2309-2319.

B obe G., Young J.W., B e it z D.C. (2004). Invited review: Pathology, etiology, prevention, and treatment of fatty liver in dairy cows. J. Dairy Sci., 87: 3105-3124.

Bron i cki M., Dembińs ki Z. (1994). Assessment of liver enzymes activity in milk of cows in relation to selected indicators for lipid metabolism. Med. Weter., 50: 268-271.

Brs c i c M., Cozzi G., Lor a I., S tefani A.L., Contiero B., Ravarotto L., Gottardo F. (2015). Reference limits for blood analytes in Holstein late-pregnant heifers and dry cows: Effects of parity, days relative to calving, and season. J. Dairy Sci., 98: 7886-7892.

C o o k N., O e tzelg G., N ordl und K. (2006). Modern techniques for monitoring high-producing dairy cows 1. Practical applications. In Pract., 28: 598-603.

Cozzi G., Ravarotto L., Gottardo F., Stefani A.L., Contiero B., Moro L., Brs c i c M., D a l v it P. (2011). Reference values for blood parameters in Holstein dairy cows: Effects of parity, stage of lactation, and season of production. J. Dairy Sci., 94: 3895-3901.

D a v o u di S.M. (2013). Study of hepatic problems in livestock. Euro J. Zool. Res., 2: 124-132.

Djokovic R., Samanc H., Jovanovic M., Fratic N., Doskovic V., Stanimirovi c Z. (2013). Relationships among blood indicators of hepatic functions and lipid content in the liver during transitional period in high-yielding dairy cows. Acta Sci. Vet., 41: 1-6.

Djoković R., Cincovic M., Ilic Z., Kurćubic V., Andjelic B., Petrović M., La1 i c N., J a s ovi c B. (2019). Relationships between contents of biochemical metabolites in blood and milk in dairy cows during transition and mid lactation. Int. J. Appl. Res. Vet. Med., 17: 1-9.

Es p os ito G., Irons P.C., Web b E.C., Chapw a n y A. (2014). Interactions between negative energy balance, metabolic diseases, uterine health and immune response in transition dairy cows Anim. Reprod. Sci., 144: 60-71.

F arid A.S., Hon kaw a K., F a th E.M., N on a ka N., H ori i Y. (2013). Serum paraoxonase-1 as biomarker for improved diagnosis of fatty liver in dairy cows. BMC Vet. Res., 9: 73.

F i l i p e j o vá T., K o vá č i k J. (2009). Evaluation of selected biochemical parameters in blood plasma, urine and milk of dairy cows during the lactation period. Slovak J. Anim. Sci., 42 (suppl.1): $8-12$.

Gilk S.D., C o ckrell D.C., Lu te rb a ch C., Han s e n B., Knodle r L.A., et al. (2013). Bacterial colonization of host cells in the absence of cholesterol. PLoS Pathog., 9(1): e1003107.

G off J.P. (2006). Major advances in our understanding of nutritional influence on bovine health. J. Dairy Sci., 89: 1292-1301.

Gonza lez F.D., Murino R., P ere ir a V., Campos R., B en ed i to J.L. (2011). Relationship among blood indicators of lipomobilization and hepatic function during early lactation in highyielding dairy cows. J. Vet. Sci., 12: 251-255.

Jóźwik A., Strzałkowska N., Bagnicka E., Grzybek W., Krzyżewski J., Poław s k a E., K oła taj A., H o r bań c z u k J.O. (2012). Relationship between milk yield, stage of lactation, and some blood serum metabolic parameters of dairy cows. Czech J. Anim. Sci., 57: 353-360. 
Kalaitzakis E., R oubies N., Panous is N., P ourliot is K., Kaldrymidou E., Karat z i a s H. (2006). Evaluation of ornithine carbamoyl transferase and other serum and liver-derived analytes in diagnosis of fatty liver and postsurgical outcome of left-displaced abomasum in dairy cows. J. Am. Vet. Med. Assoc., 229: 1463-1471.

Kalaitzakis E., Roubies N., Panous is N., P ourliot is K., Kaldrymidou E., Karat zi a s H. (2007). Clinicopathologic evaluation of hepatic lipidosis in peri-parturient dairy cattle. J. Vet. Int. Med., 21: 835-845.

Ku p c z yńs ki R., A d a m s ki M., F a lt a D., Chládek G., Kruszyńs ki W. (2011). The influence of condition on the metabolic profile of Czech Fleckvieh cows in the perinatal period. Arch. Anim. Breed., 54: 456-467.

L e B 1 a n c S.J. (2010). Monitoring metabolic health of dairy cattle in transition period. J. Reprod. Dev., 56 (Suppl 1): 29-35.

L e B l a n c S.J. (2011). The association of serum metabolites with clinical disease during the transition period. J. Dairy Sci., 94: 4897-4903.

L e B l a n c S.J. (2012). Interactions of metabolism, inflammation and reproductive tract in postpartum period in dairy cattle. Reprod. Domest. Anim., 47(Suppl 5): 18-30.

Li e s ke B., J a n t z A., F in ke B. (2005). An improved analytical approach for the determination of bovine serum albumin in milk. Lait, 85: 237-248.

L in Y., S un X., Hou X., Qu B., G a o X., Li Q. (2016). Effects of glucose on lactose synthesis in mammary epithelial cells from dairy cow BMC Vet. Res., 12: 81.

L i p p i G., Targher G., Gu id i G.C. (2007). Relationship between $\gamma$-glutamyltransferase, fasting plasma glucose, and triglycerides in the general population. Clin. Chem., 53: 1866-1867.

Liu Q., Wang C., Guo G., Huo W.J., Zhang S.L., Pei C.X., Zhang Y.L., Wang H. (2018). Effects of branched-chain volatile fatty acids on lactation performance and mRNA expression of genes related to fatty acid synthesis in mammary gland of dairy cows. Animal, 12: 2071-2079.

Malek dos Reis C.B., B arreiro J.R., Moreno J.F.G., Porcionato M.A.F., S a nto s M.V. (2011). Evaluation of somatic cell count thresholds to detect subclinical mastitis in Gyr cows. J. Dairy Sci., 94: 4406-4412.

Meyer D.J., Harve y J.W. (2004). Veterinary Laboratory Medicine: Interpretation \& Diagnosis. Saunders, St. Louis, MO.

Mordak R., Ni c poń J. (2006). Selected blood parameters in cows at the periparturient period and increasing lactation. Med. Weter., 62: 1292-1294.

M or d a k R., S t e w a r t P.A. (2015). Periparturient stress and immune suppression as a potential cause of retained placenta in highly productive dairy cows: examples of prevention. Acta Vet. Scand., 57: 84.

N ord 1 und K. (2005). Herd-based monitors and tests for dairy cow and calf problems. Cattle Pract., 13: 87-92.

O g u ro H. (2019). The roles of cholesterol and its metabolites in normal and malignant hematopoiesis. Front. Endocrinol., 10: 204.

O le chnow i c z J., J a śk ow s k i J.M. (2012). Somatic cells count in cow's bulk tank milk. J. Vet. Med. Sci., 74: 681-686.

R e z a e i R., Wu Z., H o u Y., B a z er F.W., Wu G. (2016). Amino acids and mammary gland development: nutritional implications for milk production and neonatal growth. J. Anim. Sci. Biotechnol., 7: 20 .

R i m a c H., B oj i ć M. (2017). Human serum albumin - the most important transport protein in the blood. Farmaceutski Glasnik, 73: 793-808.

Sankaranarayanan S., Llera-Moya M., Drazul-Schrader D., Phillips M.C, Kellner-Weibel G., Rothblat G.H. (2013). Serum albumin acts as a shuttle to enhance cholesterol efflux from cells J. Lipid Res., 54: 671-676.

S e m a c a n A. (2005). Liver function in cows with retained placenta. Turk. J. Vet. Anim. Sci., 29: $775-778$.

S t a u fen bi el R., G e 1 fert C.C. (2004). Metabolic profile test as a management tool in dairy herds. Proc. 5th Middle-European Buiatrics Congress, Hajduszoboszlo, Hungary 2-5.06.2004, p.721.

S t a u fen bi el R., A h m ed M.M., B a u m gartner W., G e lfert C.C. (2007). The use biochemi- 
cal and hepatic parameters to predict treatment outcome of dairy cows suffering from displacement of the abomasum. Dtsch. Tierarztl.Wochenschr., 114: 225-230.

Stojević Z., Piršljin J., Milinković-Tur S., Zdelar-Tuk M., Beer Ljubić B. (2005) Activities of AST, ALT and GGT in clinically healthy dairy cows during lactation and in the dry period. Vet. Arhiv., 75: 67-73.

Ta 11 A.R., Yvan-Charvet L. (2015). Cholesterol, inflammation and innate immunity. Nat. Rev. Immunol., 15: 104-116.

Tan a k a H., Shiban o K., Monji Y., Kaw a y a ma T., I w a t a H. (2013) Liver condition affects bovine oocyte qualities by changing the characteristics of follicular fluid and plasma. Reprod. Domest. Anim., 48: 619-626.

Vranković L., Aladrović J., Octenjak D., Bijelić D., Cvetnić L., Stojević Z. (2017). Milk fatty acid composition as an indicator of energy status in Holstein dairy cows. Arch. Anim. Breed., 60: 205-212.

Whit a ker D.A., M a crae A.I., Burrough E. (2005). Nutrition, fertility and dairy herd productivity. Cattle Pract., 13: 27-32.

Received: 22 VIII 2019

Accepted: 7 II 2020 